\title{
Extubation Readiness in Preterm Infants: Evaluating the Role of Monitoring Intermittent Hypoxemia
}

\author{
Elie G. Abu Jawdeh ${ }^{1, *(-)}$, Amrita Pant ${ }^{2}$, Aayush Gabrani ${ }^{3}{ }^{(\mathcal{D}}$, M. Douglas Cunningham ${ }^{1}$, Thomas M. Raffay ${ }^{4}(\mathbb{D}$ \\ and Philip M. Westgate ${ }^{5}$ \\ 1 Division of Neonatology, Department of Pediatrics, College of Medicine, University of Kentucky, Lexington, \\ KY 40508, USA; doug.cunningham@uky.edu \\ 2 Department of Pediatrics, McLaren Regional Medical Center, Flint, MI 48532, USA; amrita.pant@mclaren.org \\ 3 Division of Pediatric Gastroenterology, Hepatology and Nutrition, Department of Pediatrics, University of \\ Texas Southwestern, Dallas, TX 75390, USA; aayush.gabrani@utsouthwestern.edu \\ 4 Division of Neonatology, Department of Pediatrics, College of Medicine, Case Western Reserve University, \\ Cleveland, OH 44106, USA; tmr12@case.edu \\ 5 Department of Biostatistics, College of Public Health, University of Kentucky, Lexington, KY 40536, USA; \\ philip.westgate@uky.edu \\ * Correspondence: elie.abujawdeh@uky.edu
}

Citation: Abu Jawdeh, E.G.; Pant, A.; Gabrani, A.; Cunningham, M.D.;

Raffay, T.M.; Westgate, P.M.

Extubation Readiness in Preterm Infants: Evaluating the Role of

Monitoring Intermittent Hypoxemia.

Children 2021, 8, 237. https://

doi.org/10.3390/children8030237

Academic Editor: Vineet Bhandari

Received: 13 February 2021

Accepted: 10 March 2021

Published: 18 March 2021

Publisher's Note: MDPI stays neutral with regard to jurisdictional claims in published maps and institutional affiliations.

Copyright: (c) 2021 by the authors. Licensee MDPI, Basel, Switzerland. This article is an open access article distributed under the terms and conditions of the Creative Commons Attribution (CC BY) license (https:// creativecommons.org/licenses/by/ $4.0 /)$.

\begin{abstract}
Preterm infants with respiratory distress may require mechanical ventilation which is associated with increased pulmonary morbidities. Prompt and successful extubation to noninvasive support is a pressing goal. In this communication, we show original data that increased recurring intermittent hypoxemia $(\mathrm{IH}$, oxygen saturation $<80 \%$ ) may be associated with extubation failure at $72 \mathrm{~h}$ in a cohort of neonates $<30$ weeks gestational age. Current-generation bedside high-resolution pulse oximeters provide saturation profiles that may be of use in identifying extubation readiness and failure. A larger prospective study that utilizes intermittent hypoxemia as an adjunct predictor for extubation readiness is warranted.
\end{abstract}

Keywords: extubation; intubation; intermittent hypoxemia; preterm; respiratory distress

\section{Introduction}

Mechanical ventilation is common in preterm infants in the treatment of respiratory distress and respiratory failure [1]. Although essential and lifesaving, prolonged mechanical ventilation is associated with increased morbidities [2]. Nevertheless, untimely extubation may also be harmful, as failure and subsequent reintubation is associated with increased morbidity and mortality as well [3-5]. Therefore, it is imperative that a timely and safe extubation be undertaken to shorten the duration of mechanical ventilation after the resolution of respiratory distress. However, there are no standardized processes to assess for extubation readiness and marked variation among neonatal intensive care units (NICUs) persists [6]. Multiple strategies have been investigated, such as use of minute ventilation $[7,8]$, spontaneous breathing tests [9], pulmonary and respiratory testing [10-12], cardiorespiratory variability [11,13-16], and diverse demographics and ventilator modes [17-21], all with variable success. The utility of the aforementioned predictors is inconsistent or of limited availability at the bedside. Consequently, an objective, feasible, and readily available assessment for extubation readiness is yet to be determined [22].

Pulse oximetry is commonly used in clinical practice, with adapted capabilities to calculate and display cumulative intermittent hypoxemia $(\mathrm{IH})$ in the form of oxygen saturation $\left(\mathrm{SpO}_{2}\right)$ histograms. Intermittent hypoxemia is likely underutilized in assessing extubation readiness, since $\mathrm{IH}$ is the result of both lung disease and respiratory instability in preterm infants [23-26]. In this communication, we explore the value of IH in extubation successes and failures in preterm infants. 


\section{Materials and Methods}

Infants $<30$ weeks gestational age (GA) were prospectively enrolled upon admission to the neonatal intensive care unit (NICU). High-resolution $\mathrm{SpO}_{2}$ data were collected (sampling rate: $1 \mathrm{~Hz}$, averaging time: $2 \mathrm{~s}$ ) and archived as previously described [27]. Respiratory support and extubation data were retrospectively collected from the medical records. Data timestamps related to $\mathrm{IH}$ and respiratory support were well organized in a research database or medical records flow sheets, respectively. Informed consent was obtained prior to $\mathrm{SpO}_{2}$ data collection. The study was approved by the University of Kentucky's Institutional Review Board.

$\mathrm{IH}$ is calculated as percent time spent with hypoxemia $\left(\mathrm{SpO}_{2}<80 \%\right)$ and number of events per day when $\mathrm{SpO}_{2}$ dropped to less than $80 \%$ for a $4-180 \mathrm{~s}$ duration $[28,29]$. Software created through Matlab was utilized to quantify IH measures [29]. IH measures were reported $24 \mathrm{~h}$ pre-extubation until $72 \mathrm{~h}$ post-extubation (or when reintubation became necessary).

At our institution, patients are considered for extubation when initial respiratory distress has improved and standardized readiness criteria are met (synchronized intermittent mandatory ventilation respiratory rate $(R R) \leq 20$ breaths $/ \mathrm{min}$, fraction of inspired oxygen $\left(\mathrm{FiO}_{2}\right) \leq 40 \%$, peak end expiratory pressure (PEEP) $\leq 6 \mathrm{cmH} 2 \mathrm{O}$, peak inspiratory pressure (PIP) $\leq 20 \mathrm{cmH}_{2} \mathrm{O}$, and tidal volume $(\mathrm{Vt}) \leq 6 \mathrm{~mL} / \mathrm{kg}$ ). All infants were extubated to non-invasive nasal support. We defined failure as reintubation within $72 \mathrm{~h}$. Extubation events were grouped as successes or failures.

Statistical analyses were conducted in SAS Version 9.4 software (SAS Institute, Cary, $\mathrm{NC}, \mathrm{USA}$ ). Group comparisons of mean values for the percent time (\%time $\mathrm{IH}-\mathrm{SpO}_{2}<80$ ) and the number of events $\left(\mathrm{IH}-\mathrm{SpO}_{2}<80\right)$ were square root transformed, if necessary, in order to meet statistical assumptions as previously described [30]. Primary analyses defined failure as re-intubation before $72 \mathrm{~h}$ post-extubation. Receiver operating characteristic (ROC) curve analyses were used to find optimal cutoff values. Secondary analyses examined differences between groups at $24 \mathrm{~h}$ post-extubation. All tests were two-sided at the $5 \%$ significance level.

\section{Results}

Of the 91 extubations identified, a total of 68 extubation occurrences from 50 preterm infants $<30$ weeks of gestation had complete data sets and were therefore included. Demographics and respiratory support data are presented in Table 1. Median GAs were 26-6/7 weeks and 25-5/7 weeks in success and failure groups, respectively. All infants were extubated from conventional ventilator support to continuous positive airway pressure (CPAP) or noninvasive positive-pressure ventilation (NIPPV). Overall, most extubation attempts were successful ( $72 \%$ of events were successful at $72 \mathrm{~h})$. As this was a pilot, we were not appropriately powered to detect group differences. Medians and interquartile-ranges are provided.

Continuous $\mathrm{SpO}_{2}$ waveforms were interrogated for $\mathrm{IH}$ events and $\mathrm{SpO}_{2}$ histograms before and after extubation. Differences in $\mathrm{IH}$ measures between failure and success groups are represented in Figure 1; both \%time- $\mathrm{SpO}_{2}<80$ and $\mathrm{IH}-\mathrm{SpO}_{2}<80$ were higher in the failure group compared to successful group pre- and post-extubation, however, differences were not statistically significant. On the secondary analyses for differences in $24 \mathrm{~h}$ postextubation, there were also increased IH measures in the failure group compared to the success group (\%time- $\mathrm{SpO}_{2}<80, p=0.07$, and $\mathrm{IH}-\mathrm{SpO}_{2}<80, p=0.03$ ). Interestingly, there was a statistically significant decrease in IH after extubation in the success group in both the primary $(72 \mathrm{~h})$ and secondary $(24 \mathrm{~h})$ analyses (all $p<0.01)$ (Figure 1$)$. The differences in IH measures remained the same after adjusting for GA, birth weight, weight, and day of life at time of extubation. We applied the same analyses to the first extubation events only; these results were similar in IH trends. 
Table 1. Demographics and respiratory characteristics.

\begin{tabular}{|c|c|c|}
\hline Baseline Characteristics & $\begin{array}{c}\text { Success } \\
n=49\end{array}$ & $\begin{array}{c}\text { Failure } \\
n=19\end{array}$ \\
\hline Gestational age (weeks) & $26.6(25.3-27.6)$ & $25.5(25.1-26.1)$ \\
\hline Birth weight (grams) & $890(730-1040)$ & $730(650-905)$ \\
\hline Weight at time of extubation (grams) & $1140(960-1253)$ & $970(830-1150)$ \\
\hline Age at time of extubation (days) & $18(5-37)$ & $21(9-33)$ \\
\hline \multicolumn{3}{|l|}{ Baseline Ventilator Setting } \\
\hline - Set respiratory rate (breaths / $\mathrm{min}$ ) & $15(15-20)$ & $20(15-20)$ \\
\hline - $\mathrm{FiO}_{2}(\%)$ & $25(21-30)$ & $29(25-32)$ \\
\hline - $\operatorname{PEEP}\left(\mathrm{cmH}_{2} \mathrm{O}\right)$ & $6(5-6)$ & $6(6-7)$ \\
\hline - $\mathrm{PIP}\left(\mathrm{cmH}_{2} \mathrm{O}\right)$ & $15(13-21)$ & $16(13-18)$ \\
\hline - $\mathrm{TV}(\mathrm{mL} / \mathrm{kg})$ & $5(5-6)$ & $5(4-6)$ \\
\hline \multicolumn{3}{|l|}{ Post-extubation non-invasive support } \\
\hline - CPAP & $10 / 49(20 \%)$ & $0 / 19(0 \%)$ \\
\hline - NIPPV & $39 / 49(79 \%)$ & $19 / 19(100 \%)$ \\
\hline - $\mathrm{FiO}_{2}(\%)$ & $32(25-38)$ & $40(30-44)$ \\
\hline - $\operatorname{PEEP}\left(\mathrm{cmH}_{2} \mathrm{O}\right)$ & $7(6-8)$ & $8(7-9)$ \\
\hline
\end{tabular}

Median (interquartile range). $\mathrm{FiO}_{2}$ : fraction of inspired oxygen, PEEP: positive end expiratory pressure, PIP: peak inspiratory pressure, TV: Tidal volume. CPAP: Continuous positive airway pressure. NIPPV: Noninvasive positive-pressure ventilation.

A

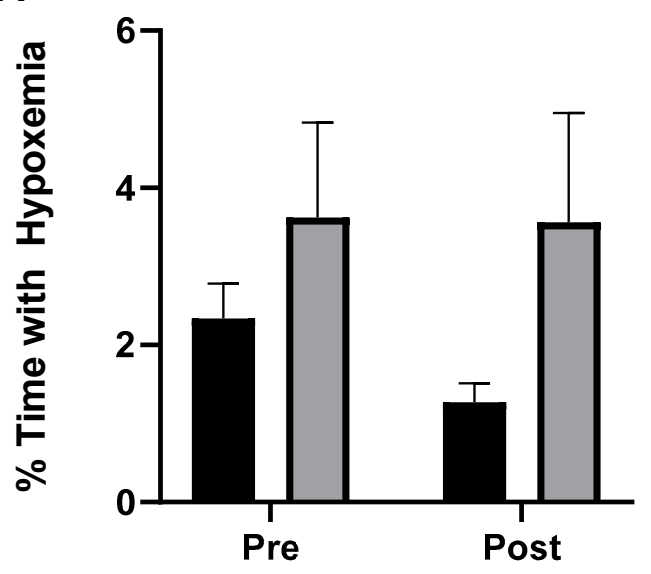

B

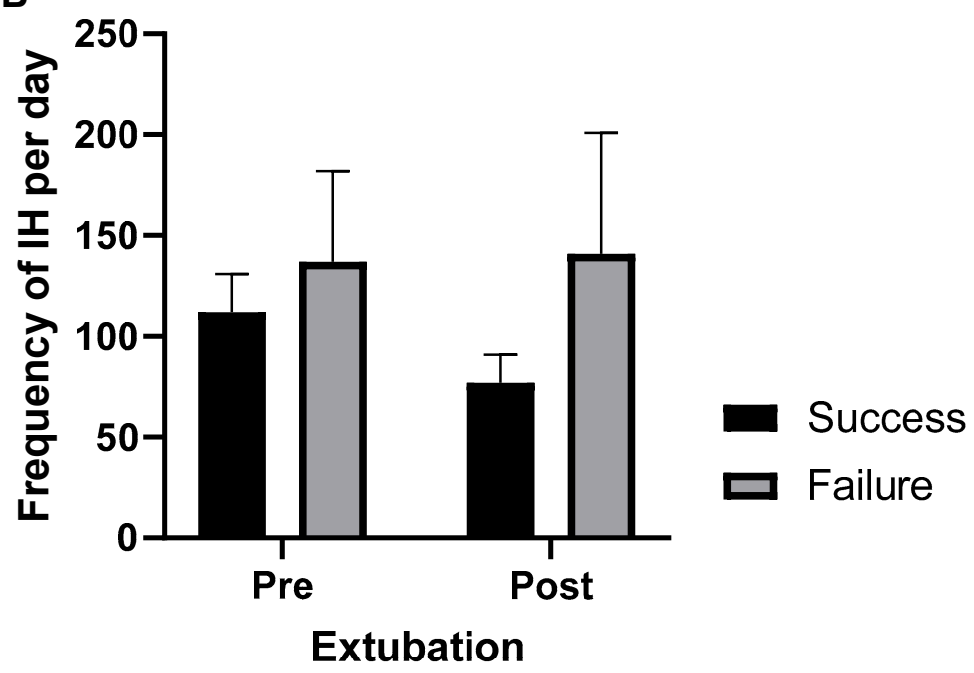

Figure 1. Intermittent hypoxemia (IH) measures $24 \mathrm{~h}$ pre- and up to $72 \mathrm{~h}$ post-extubation in success and failure groups. (A) Percent time in hypoxemia. (B) Frequency of IH. Mean $\pm \mathrm{SE}$. 
Based on the ROC assessment, the optimal cutoffs of pre-extubation IH measures associated with successful extubation were calculated. The cutoff of $193 \mathrm{IH}-\mathrm{SpO}_{2}<80$ per day and $7.5 \%$ with $\%$ time- $\mathrm{SpO}_{2}<80 \%$ had the highest sum of sensitivity and specificity. Example 1: if a patient had less than $193 \mathrm{IH}$ events/day during the $24 \mathrm{~h}$ prior to extubation, there is a $73 \%$ likelihood of successful extubation for the patient. Example 2: if a patient who spent more than $7.5 \%$ of the time with $\mathrm{SpO} 2<80 \%$ per day were to be extubated, there is an $86 \%$ likelihood of failure for that patient.

\section{Discussion}

These pilot data demonstrate a potential and valuable role for IH in extubation success or failure in preterm infants. First, there was a trend for increased $\mathrm{IH}$ pre-extubation in the failure group as compared to the success group. Given that this was a pilot assessment with a limited sample size, these data support the need for a larger appropriately powered investigation of $\mathrm{IH}$ as a risk-predictor of extubation readiness. Second, the same trend between failure and success groups occurred post-extubation, indicating a potential role of IH in early detection of impending failures and prompt re-intubation. It has been reported that infants continue to have frequent IH events during mechanical ventilation [31]. Here, we document that infants who had successful extubations had a subsequent significant decrease in IH measures post-extubation. This interesting phenomenon may be useful for early identification of extubation success versus failure. IH may prove to be a reliable marker for both timely identification of extubation readiness and impending failure, lending to safe reinsertion of the endotracheal tube. Many studies have investigated extubation readiness in preterm infants [7-21]. Some studies utilized techniques such as pulmonary function testing that, although valuable, are not readily available at the bedside in every NICU. Other studies focused on ventilator settings and measures to assess for readiness. However, not all ventilators settings are weaned in a timely manner, and most may not provide accurate measurements of pulmonary mechanics. The value of $\mathrm{IH}$, as derived from the $\mathrm{SpO}_{2}$ histogram, is both readily available in all NICUs and often an accurate consequence of a cardio-respiratory compromise. Limitations include the single-center retrospective nature of this study and limited power. In addition, while NICU criteria for extubation are in place, the final decision to extubate, or the need to reintubate remained at the discretion of the treating clinical team. Due to some subjects contributing multiple extubation observations, as well as the need to statistically account for repeated measures across time (preand post-extubation) from the same observations, multilevel modeling was employed, and thus we were under-powered to detect a significant difference. However, this is a novel study as the value of $\mathrm{IH}$ has not been examined in this setting.

Utilization of the bedside $\mathrm{SpO}_{2}$ histogram for cumulative $\mathrm{IH}$ as a predictor for extubation readiness may be a pragmatic answer for this decades-long problem of when is the optimal time to extubate infants recovering from respiratory distress [22]. Intermittent hypoxemia is a promising, objective, and feasible adjunct predictor for extubation readiness, as percent time with hypoxemia is readily available; often stored in the NICU bedside monitors for more than $24 \mathrm{~h}\left(\mathrm{SpO}_{2}\right.$ histogram). This is a pilot assessment, and we caution the readers from early implementation of the IH thresholds identified in this manuscript. We plan on a larger study to better define IH thresholds predictive of extubation success or failure in preterm infants.

\section{Conclusions}

Since IH is the result of respiratory instability and lung disease, we propose identifying cumulative $\mathrm{IH}\left(\mathrm{SpO}_{2}\right.$ histogram $)$ as a valuable tool that guides clinicians' decision making regarding extubation readiness or impending failure. A larger prospective study that utilizes IH as an adjunct predictor for extubation readiness is warranted.

Author Contributions: Conceptualization: E.G.A.J., A.P., M.D.C., T.M.R., and P.M.W.; methodology: E.G.A.J., A.P., A.G., and P.M.W.; data collection: E.G.A.J., A.P., and A.G.; analysis: E.G.A.J., A.P., and P.M.W.; data interpretation: E.G.A.J., M.D.C., T.M.R., and P.M.W.; draft preparation: E.G.A.J., T.M.R., 
and P.M.W.; review and editing A.P. and M.D.C. All authors have read and agreed to the published version of the manuscript.

Funding: The study was funded in part by: (1) The Gerber Foundation (EGA, PI), (2) University of Kentucky's National Center for Advancing Translational Sciences, UL1RR033173, and (3) TMR is supported by the NIH K08HL133459-04 grant.

Institutional Review Board Statement: The study was conducted according to the guidelines of the Declaration of Helsinki and approved by the Institutional Review Board of University of Kentucky (protocol code 43669 and date of approval 03/2018).

Informed Consent Statement: Written informed consent was obtained from all subjects involved in the study.

Data Availability Statement: The data presented in this study are available on request from the corresponding author.

Acknowledgments: We thank the support of the NICU research staff and nurses. We thank Divya Mamilla, for data collection. We thank Henrietta Bada, Abhijit Patwardhan, Peter Giannone, and Mandy Brasher, for various contributions. Portions of these data were presented at the 2017 Pediatric Academic Societies International Meeting, San Francisco, CA.

Conflicts of Interest: The authors declare no conflict of interest.

\section{References}

1. Stoll, B.J.; Hansen, N.I.; Bell, E.F.; Walsh, M.C.; Carlo, W.A.; Shankaran, S. Eunice kennedy shriver national institute of child health. Trends in Care Practices, Morbidity, and Mortality of Extremely Preterm Neonates, 1993-2012. JAMA 2015, 314, $1039-1051$. [CrossRef]

2. Walsh, M.C.; Morris, B.H.; Wrage, L.A.; Vohr, B.R.; Poole, W.K.; Tyson, J.E.; Wright, L.L.; Ehrenkranz, R.A.; Stoll, B.J.; Fanaroff, A.A. Extremely low birthweight neonates with protracted ventilation: Mortality and 18-month neurodevelopmental outcomes. J. Pediatr. 2005, 146, 798-804. [CrossRef] [PubMed]

3. Guardia, C.G.; Moya, F.R.; Sinha, S.; Gadzinowski, J.; Donn, S.M.; Simmons, P.; Segal, R. Reintubation and risk of morbidity and mortality in preterm infants after surfactant replacement therapy. J. Neonatal Perinat. Med. 2011, 4, 101-109. [CrossRef]

4. Baisch, S.D.; Wheeler, W.B.; Kurachek, S.C.; Cornfield, D.N. Extubation failure in pediatric intensive care incidence and outcomes. Pediatr. Crit. Care Med. 2005, 6, 312-318. [CrossRef] [PubMed]

5. Pavlek, L.R.; Dillard, J.; Ryshen, G.; Hone, E.; Shepherd, E.G.; Moallem, M. Short-term complications and long-term morbidities associated with repeated unplanned extubations. J. Perinatol. 2021, 1-9. [CrossRef]

6. Al-Mandari, H.; Shalish, W.; Dempsey, E.; Keszler, M.; Davis, P.G.; Sant'Anna, G. International survey on periextubation practices in extremely preterm infants. Arch. Dis. Child. Fetal Neonatal Ed. 2015, 100, F428-F431. [CrossRef]

7. Gillespie, L.M.; White, S.D.; Sinha, S.K.; Donn, S.M. Usefulness of the minute ventilation test in predicting successful extubation in newborn infants: A randomized controlled trial. J. Perinatol. 2003, 23, 205-207. [CrossRef]

8. Wilson, B.J., Jr.; Becker, M.A.; Linton, M.E.; Donn, S.M. Spontaneous minute ventilation predicts readiness for extubation in mechanically ventilated preterm infants. J. Perinatol. 1998, 18, 436-439.

9. Shalish, W.; Kanbar, L.; Kovacs, L.; Chawla, S.; Keszler, M.; Rao, S.; Latremouille, S.; Precup, D.; Brown, K.; Kearney, R.E.; et al. Assessment of Extubation Readiness Using Spontaneous Breathing Trials in Extremely Preterm Neonates. JAMA Pediatr. 2020, 174, 178-185. [CrossRef] [PubMed]

10. Robles-Rubio, C.A.; Kaczmarek, J.; Chawla, S.; Kovacs, L.; Brown, K.A.; Kearney, R.E.; Sant Anna, G.M. Automated analysis of respiratory behavior in extremely preterm infants and extubation readiness. Pediatr. Pulmonol. 2015, 50, 479-486. [CrossRef]

11. Veness-Meehan, K.A.; Richter, S.; Davis, J.M. Pulmonary function testing prior to extubation in infants with respiratory distress syndrome. Pediatr. Pulmonol. 1990, 9, 2-6. [CrossRef]

12. Balsan, M.J.; Jones, J.G.; Watchko, J.F.; Guthrie, R.D. Measurements of pulmonary mechanics prior to the elective extubation of neonates. Pediatr. Pulmonol. 1990, 9, 238-243. [CrossRef]

13. Kaczmarek, J.; Chawla, S.; Marchica, C.; Dwaihy, M.; Grundy, L.; Sant'Anna, G.M. Heart rate variability and extubation readiness in extremely preterm infants. Neonatology 2013, 104, 42-48. [CrossRef]

14. Kaczmarek, J.; Kamlin, C.O.; Morley, C.J.; Davis, P.G.; Sant'anna, G.M. Variability of respiratory parameters and extubation readiness in ventilated neonates. Arch. Dis. Child. Fetal Neonatal Ed. 2013, 98, F70-F73. [CrossRef]

15. Precup, D.; Robles-Rubio, C.A.; Brown, K.A.; Kanbar, L.; Kaczmarek, J.; Chawla, S.; Sant'Anna, G.M.; Kearney, R.E. Prediction of extubation readiness in extreme preterm infants based on measures of cardiorespiratory variability. Conf. Proc. IEEE Eng. Med. Biol. Soc. 2012, 2012, 5630-5633. [CrossRef]

16. Szymankiewicz, M.; Vidyasagar, D.; Gadzinowski, J. Predictors of successful extubation of preterm low-birth-weight infants with respiratory distress syndrome. Pediatr. Crit. Care Med. 2005, 6, 44-49. [CrossRef] 
17. De Jaegere, A.; van Veenendaal, M.B.; Michiels, A.; van Kaam, A.H. Lung recruitment using oxygenation during open lung high-frequency ventilation in preterm infants. Am. J. Respir. Crit. Care Med. 2006, 174, 639-645. [CrossRef] [PubMed]

18. Reyes, Z.C.; Claure, N.; Tauscher, M.K.; D’Ugard, C.; Vanbuskirk, S.; Bancalari, E. Randomized, controlled trial comparing synchronized intermittent mandatory ventilation and synchronized intermittent mandatory ventilation plus pressure support in preterm infants. Pediatrics 2006, 118, 1409-1417. [CrossRef] [PubMed]

19. Shefali-Patel, D.; Murthy, V.; Hannam, S.; Lee, S.; Rafferty, G.F.; Greenough, A. Randomised weaning trial comparing assist control to pressure support ventilation. Arch. Dis. Child. Fetal Neonatal Ed. 2012, 97, F429-F433. [CrossRef] [PubMed]

20. Wheeler, K.; Klingenberg, C.; McCallion, N.; Morley, C.J.; Davis, P.G. Volume-targeted versus pressure-limited ventilation in the neonate. Cochrane Database Syst. Rev. 2010, 11, CD003666. [CrossRef]

21. Sant'Anna, G.M.; Keszler, M. Weaning infants from mechanical ventilation. Clin. Perinatol. 2012, 39, 543-562. [CrossRef] [PubMed]

22. Gupta, D.; Greenberg, R.G.; Sharma, A.; Natarajan, G.; Cotten, M.; Thomas, R.; Chawla, S. A predictive model for extubation readiness in extremely preterm infants. J. Perinatol. 2019, 39, 1663-1669. [CrossRef] [PubMed]

23. Rhein, L.M.; Dobson, N.R.; Darnall, R.A.; Corwin, M.J.; Heeren, T.C.; Poets, C.F.; McEntire, B.L.; Hunt, C.E.; The Caffeine Pilot Study Group. Effects of caffeine on intermittent hypoxia in infants born prematurely: A randomized clinical trial. JAMA Pediatr. 2014, 168, 250-257. [CrossRef] [PubMed]

24. Poets, C.F.; Roberts, R.S.; Schmidt, B.; Whyte, R.K.; Asztalos, E.V.; Bader, D.; Bairam, A.; Moddemann, D.; Peliowski, A.; Rabi, Y.; et al. Association Between Intermittent Hypoxemia or Bradycardia and Late Death or Disability in Extremely Preterm Infants. JAMA 2015, 314, 595-603. [CrossRef]

25. Walsh, M.C.; Di Fiore, J.M.; Martin, R.J.; Gantz, M.; Carlo, W.A.; Finer, N. Association of Oxygen Target and Growth Status with Increased Mortality in Small for Gestational Age Infants: Further Analysis of the Surfactant, Positive Pressure and Pulse Oximetry Randomized Trial. JAMA Pediatr. 2016, 170, 292-294. [CrossRef]

26. Martin, R.J.; Di Fiore, J.M.; Walsh, M.C. Hypoxic Episodes in Bronchopulmonary Dysplasia. Clin. Perinatol. 2015, 42, 825-838. [CrossRef]

27. Ibonia, K.T.; Bada, H.S.; Westgate, P.M.; Gomez-Pomar, E.; Bhandary, P.; Patwardhan, A.; Abu Jawdeh, E.G. Blood transfusions in preterm infants: Changes on perfusion index and intermittent hypoxemia. Transfusion 2018, 58, 2538-2544. [CrossRef]

28. Abu Jawdeh, E.G.; Martin, R.J.; Dick, T.E.; Walsh, M.C.; Di Fiore, J.M. The effect of red blood cell transfusion on intermittent hypoxemia in ELBW infants. J. Perinatol. 2014, 34, 921-925. [CrossRef]

29. Abu Jawdeh, E.G. Intermittent Hypoxemia in Preterm Infants. Ph.D. Dissertation, University of Kentucky, Lexington, KY, USA, 2018. [CrossRef]

30. Abu Jawdeh, E.G.; Westgate, P.M.; Pant, A.; Stacy, A.L.; Mamilla, D.; Gabrani, A.; Patwardhan, A.; Bada, H.S.; Giannone, P. Prenatal Opioid Exposure and Intermittent Hypoxemia in Preterm Infants: A Retrospective Assessment. Front. Pediatr. 2017, 5 , 253. [CrossRef]

31. Bancalari, E.; Claure, N. Respiratory Instability and Hypoxemia Episodes in Preterm Infants. Am. J. Perinatol. 2018, 35, 534-536. [CrossRef] 